OPEN ACCESS

Edited by:

Laura Haynes,

University of Connecticut,

United States

Reviewed by:

Kerrie L. Moreau,

University of Colorado Anschutz

Medical Campus, United States

Ramalakshmi Ramasamy,

UConn Health, United States

*Correspondence:

Ashley E. Walker

aewalker@uoregon.edu

Specialty section:

This article was submitted to Molecular Mechanisms of Aging,

a section of the journal

Frontiers in Aging

Received: 08 October 2021

Accepted: 12 November 2021

Published: 01 December 2021

Citation:

Kehmeier MN and Walker AE (2021)

Sex Differences in Large Artery

Stiffness: Implications for

Cerebrovascular Dysfunction and

Alzheimer's Disease.

Front. Aging 2:791208.

doi: 10.3389/fragi.2021.791208

\section{Sex Differences in Large Artery Stiffness: Implications for Cerebrovascular Dysfunction and Alzheimer's Disease}

\author{
Mackenzie N. Kehmeier and Ashley E. Walker* \\ Department of Human Physiology, University of Oregon, Eugene, OR, United States
}

Two in every three Alzheimer's disease diagnoses are females, calling attention to the need to understand sexual dimorphisms with aging and neurodegenerative disease progression. Dysfunction and damage to the vasculature with aging are strongly linked to Alzheimer's disease. With aging there is an increase in stiffness of the large elastic arteries, and this stiffening is associated with cerebrovascular dysfunction and cognitive impairment. However, it is unclear how the deleterious effects of arterial stiffness may differ between females and males. While environmental, chromosomal, and sex hormone factors influence aging, there is evidence that the deficiency of estrogen postmenopause in females is a contributor to vascular aging and Alzheimer's disease progression. The purpose of this mini review is to describe the recent developments in our understanding of sex differences in large artery stiffness, cerebrovascular dysfunction, and cognitive impairment, and their intricate relations. Furthermore, we will focus on the impact of the loss of estrogen post-menopause as a potential driving factor for these outcomes. Overall, a better understanding of how sex differences influence aging physiology is crucial to the prevention and treatment of neurodegenerative diseases.

Keywords: arterial stiffness, pulse pressure, endothelial cell, cerebrovascular, cognitive impairment, menopause, estrogen

\section{INTRODUCTION}

Advancing age is the biggest risk factor for late-onset Alzheimer's disease (AD), suggesting that elements of the aging process initiate or contribute to AD. In the United States, two-thirds of patients with $\mathrm{AD}$ are females (Alzheimer's Association, 2013) and the progression from mild cognitive impairment to $\mathrm{AD}$ is quicker in females than males (Lin et al., 2015). However, the causes of the increased $\mathrm{AD}$ risk in females are not entirely clear. The contribution of the aging vascular system in $\mathrm{AD}$ onset and progression is supported by recent evidence (Kapasi and Schneider, 2016). Therefore, sex differences in vascular aging represent a potential source of the greater $\mathrm{AD}$ risk in females.

A primary characteristic of vascular aging is the stiffening of the large elastic arteries. This agerelated increase in arterial stiffness is related to cognitive impairment and $\mathrm{AD}$, and it is hypothesized that cerebrovascular dysfunction links these phenomena (Iulita et al., 2018). While arterial stiffness increases with age in both sexes, there is a stronger association between arterial stiffness and mortality in females compared with males (Coutinho, 2014). Less is known about sex differences in the relations between arterial stiffness and cerebrovascular dysfunction and cognitive impairment. Sexual dimorphisms in age-related arterial stiffening, and the consequences of this stiffness, may 
explain the sex differences in AD risk, and potentially identify the need for individualized treatment. The goal of this mini review is to highlight the importance of sex differences in vascular aging and the related onset of cerebrovascular dysfunction and AD. Importantly, we will identify the major gaps in knowledge remaining. The impact of sex differences in vascular aging affects a broad range of neurological diseases. Although this mini review focuses on $\mathrm{AD}$, most of the underlying physiological processes discussed have implications for other neurological diseases.

\section{SEX HORMONES}

Sex differences in $\mathrm{AD}$ risk are likely driven by sex hormones, genotype (XX vs. XY), and sociocultural factors. In particular, the low estrogen in post-menopausal females is a contributor to vascular dysfunction when compared to pre-menopausal female and/or their male counterparts. Estrogen stimulates genomic and nongenomic cell signaling cascades by activation of estrogen receptors (ER) $\alpha$ and $\beta$, and the G-protein coupled receptor, GPER1 (or GPR30) (Zimmerman et al., 2016; Fuentes and Silveyra, 2019). These receptors are found on vascular cells as well as other cells in the brain (Pau et al., 1998; Morissette et al., 2008). Progesterone and androgens also decrease with age, while follicle stimulating hormone and luteinizing hormone increase (Lee et al., 1988; Morley, 2001). In this review, we will specifically focus on the low estrogen state in post-menopausal females given the preponderance of evidence for its importance.

\section{LARGE ARTERY STIFFNESS}

The stiffness of the large elastic arteries increases with age in both males and females; yet there are important sex differences in the causes and rate of progression of this stiffening. The term large arteries, or large elastic arteries, refers to the aorta and carotid arteries. These large arteries have a very distensible wall and a high content of elastin protein. At young ages, females tend to have more compliant large arteries compared with males, but this trend reverses in old age with older females generally having stiffer large arteries compared with males (Waddell et al., 2001; Berry et al., 2004; Coutinho, 2014). These trends result in females experiencing a more rapid increase in arterial stiffness with aging than males, as found in humans (Lu et al., 2020) and rodents (DuPont et al., 2021). This rapid period of increases in arterial stiffness occurs at $~ 55-75$ years of age in human females, corresponding to the early post-menopausal period and the reduction of estrogen. Hormone replacement therapy with estradiol typically improves arterial stiffness in postmenopausal females (Scuteri et al., 2001). In summary, agerelated increases in large artery stiffness are more rapid in females, likely due to declining estrogen post-menopause.

In general, the sources of age-related large artery stiffening are decreased elastin content, increased elastin fragmentation, increased collagen content and crosslinking, and increased vascular tone (Fonck et al., 2009; Hayashi and Hirayama,
2017). However, most of these mechanisms were studied in males and little is known about the causes of increased arterial stiffness in females. In animal studies, females have age-related increases in large artery collagen content and advanced glycation end-products, contributing to collagen cross-linking (Qiu et al., 2007; DuPont et al., 2021). Estrogen decreases collagen deposition by cultured smooth muscle cells (Natoli et al., 2005), and thus, post-menopausal females may suffer from a loss of the inhibitory actions of estrogens on arterial collagen production. In addition to differences in structural proteins, age-related arterial stiffening in females is caused by increases in arterial tone from a reduction in nitric oxide (NO) bioavailability (Scuteri et al., 2001). Interventions known to improve NO bioavailability also reduce stiffness in postmenopausal females, such as treatment with antioxidants (Moreau et al., 2005) and endothelial NO synthase (eNOS) co-factor tetrahydrobiopterin (Moreau et al., 2012). Furthermore, sympathetic nerve activity increases with age in females and has been related to large artery stiffness, potentially due to increased arterial tone or blood pressures (Harvey et al., 2017; Holwerda et al., 2019). Lastly, signaling by smooth muscle mineralocorticoid receptors contributes to increased age-related aorta stiffening, but the mechanisms appear to be different between male and female mice (DuPont et al., 2021). The causes of sex differences in large artery stiffness have been more thoroughly reviewed by Moreau and Hildreth (Moreau and Hildreth, 2014) and DuPont et al. (2019).

\section{BLOOD FLOW AND PRESSURE PULSATILITY}

As large artery stiffness increases, there is greater pulsatility of blood pressure and blow flow (Mitchell, 2018). At young ages, the large arteries are highly compliant and dampen the pulse of blood ejected from the heart. The cerebral vasculature is also protected from highly pulsatile pressure and flow due to a partial reflection of the pressure wave before it reaches the brain. This partial reflection of the pressure wave results from the mismatch of stiffness between the highly complaint aorta and the stiffer muscular arteries (Mitchell, 2018). As the aorta stiffens with age, there is less wave reflection and a higher transmission of pulsatile energy to small arteries, arterioles, and capillaries in the brain (Mitchell, 2018). It is thought that the resulting increased pressure and flow pulsatility in the cerebral vasculature leads to damage and dysfunction (de Montgolfier et al., 2019). While young females have lower cerebral artery blood flow pulsatility compared with young males (Alwatban et al., 2021), this protection does not persist into old age. In fact, the rate of increase in middle cerebral artery blood flow pulsatility with aging is greater in females than in males (Alwatban et al., 2021), corresponding to the more rapid increase in large artery stiffness in aging females. Older females also have less pulsatile dampening between the carotid and cerebral arteries compared with older males (Lefferts et al., 2020), further illustrating a higher transmission of pulsatile energy into the brain of older females. These findings suggest that the female brain at young 
ages is protected from high pulse pressures, but is exposed to a rapid increase, greater than males, in pulse pressure with aging.

\section{CEREBROVASCULAR ENDOTHELIAL DYSFUNCTION}

The age-related increase in pulse pressure in the cerebral vasculature is thought to cause endothelial cell dysfunction. The endothelium is an integral regulator of cerebral blood flow and blood brain barrier (BBB) permeability, thus agerelated dysfunction of the cerebral endothelium can lead to impairment in the brain. Endothelial cells react to stimuli by releasing several substances that cause dilation or constriction of blood vessels. At the arteriole and capillary level, a properly functioning endothelial layer is needed to coordinate the vascular, immune, and neural cells that comprise the neurovascular unit (Daneman and Prat, 2015). A key function of endothelial cells is to produce NO that signals smooth muscle cells and pericytes for relaxation (Vanhoutte et al., 2017). During aging, decreased NO bioavailability is caused by increased oxidative stress, specifically via the reaction of superoxide with NO (Donato et al., 2015). This reduction in NO bioavailability with aging can lead to an imbalance of vasodilation and vasoconstriction signals and poses a major issue for the tight regulation of cerebral blood flow.

The $\mathrm{BBB}$ protects the brain from circulating pathogens and is composed of endothelial cells joined together by tight junction proteins (Daneman and Prat, 2015). The health of endothelial cells, as well as other cells of the neurovascular unit, is important to maintaining a functional barrier. Furthermore, brain endothelial cells can tightly regulate transcytosis, limiting vesicle-mediated movement of solutes in and out of the brain (Daneman and Prat, 2015). Dysfunction of the BBB contributes to $\mathrm{AD}$ by allowing the entrance of substances (e.g., neurotoxins, immune cells) that result in increased inflammatory signaling and oxidative stress, stimulating amyloid- $\beta$ (A $\beta)$ production (Sweeney et al., 2018). A dysfunctional BBB will also lead to impaired clearance of $A \beta$ from the brain, and this impaired clearance is thought to be the primary cause of $\mathrm{A} \beta$ plaque deposition in AD (Mawuenyega et al., 2010). Thus, age-related dysfunction of endothelial cells contributes to impaired cerebral blood flow and a dysfunctional BBB.

Estrogen acts favorably on the cerebral vasculature by improving the function of endothelial cells (Krause et al., 2006), a phenomenon that is lost post-menopause. The endothelium has widely expressed $\mathrm{ER} \alpha$, and binding to this receptor results in increased eNOS expression and activation via phosphorylation, leading to greater endothelial dependent vasodilation (Haynes et al., 2000). Estrogen also decreases oxidative stress by reducing mitochondrial superoxide production (Torres et al., 2018) and increasing endogenous antioxidants (Strehlow et al., 2003). In post-menopausal females, there is decreased ERa expression in the vasculature (Gavin et al., 2009) and post-menopausal females have marked impairments in endothelial function compared with pre- menopausal females (Taddei et al., 1996). See Robinson et al. for a more thorough review of this topic (Robison et al., 2019).

The cerebral vasculature appears to be particularly susceptible to the damaging effects of increased large artery stiffness and pulse pressure. High pulse pressures applied to cerebral arteries ex vivo, as well as circumferential stress of cultured endothelial cells, leads to increased oxidative stress (Gatti et al., 2008; Raignault et al., 2017; Girão-Silva et al., 2021). Greater large artery stiffness in a rodent model leads to impaired cerebral artery endotheliumdependent vasodilation by increased oxidative stress and decreased NO bioavailability (Walker et al., 2015). Increased large artery stiffness also leads to a more permeable $\mathrm{BBB}$ in rodents (Muhire et al., 2019). However, these mechanistic studies have yet to be performed in females. It is reasonable to assume that young females are doubly protected against this phenomenon owing to lower arterial stiffness and the protective effects of estrogens directly on the endothelium. The endothelium of older females may be more susceptible to the negative consequences of large artery stiffness, but this is an area that requires more investigation.

\section{CEREBRAL BLOOD FLOW}

Cerebral endothelial cell dysfunction will disturb the tight regulation of blood flow in the brain. Young females have greater cerebral blood flow compared with males; however, the declines in cerebral blood flow with aging are greater in females, such that at old ages there are no differences in cerebral blood flow between females and males (Liu et al., 2016; Aanerud et al., 2017; DuBose et al., 2018). More important than global cerebral blood flow is the ability for local blood flow to change in response to stimuli and to be directed to working regions of the brain, indicated by cerebrovascular reactivity. Cerebrovascular reactivity declines with advancing age to a greater extent in females than males, and hormone replacement therapy can preserve cerebrovascular reactivity in post-menopausal females (Kastrup et al., 1998). The sex differences in cerebral blood flow and reactivity with aging, as well as the mechanisms, are extensively reviewed in Barnes and Charkoudian (Barnes and Charkoudian, 2021).

While sex differences in cerebral blood flow and reactivity are extensively investigated, less is known about these in relation to large artery stiffness. The association between large artery stiffness and reduced cerebral blood flow or cerebrovascular reserve has been demonstrated in human subjects, but this was independent of sex (DuBose et al., 2018) or was not analyzed for sex differences (Jefferson et al., 2018). Rodent models of induced large artery stiffness demonstrate the causeand-effect relation between large artery stiffness and reduced cerebral perfusion (Knutsen et al., 2018; Muhire et al., 2019) but these studies were performed in only male rodents. Thus, a crucial area for future research is to understand the impact of sex and sex hormones on the relation of large artery stiffness and cerebral blood flow regulation, as well as the potential modulation of this relation by other factors. 


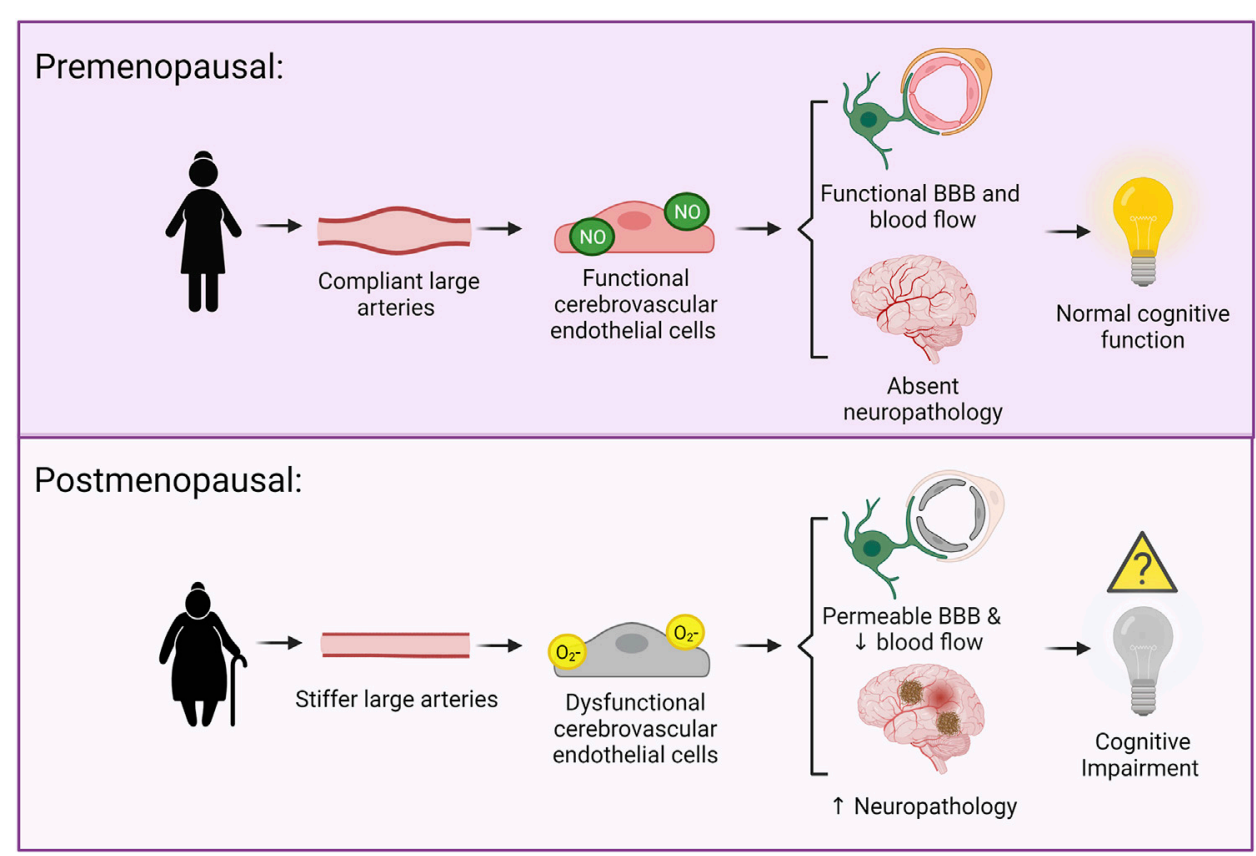

FIGURE 1 | Hypothesized mechanisms linking large artery stiffness and cognitive impairment. Above: In premenopausal females, the large arteries are compliant and cerebral pressure and blood flow pulsatility is low. This is associated with functional cerebral endothelial cells, a functional blood brain barrier, adequate cerebral blood flow, and an absence of neuropathology. Below: In postmenopausal females, there is greater large artery stiffness and higher cerebral pressure and blood flow pulsatility. This is associated with dysfunction of the cerebral endothelial cells, a more permeable blood brain barrier, neurovascular uncoupling, reduced cerebral blood flow, and increased neuropathology.

\section{NEUROPATHOLOGY}

Endothelial dysfunction, BBB permeability, and reduced cerebral blood flow are key mechanisms leading to other pathologies in the brain. For example, large artery stiffness is related to cerebral small vessel disease, a disease that is characterize by hyperintensities, cerebral microbleeds and lacunar infarcts (Mitchell et al., 2011; Poels et al., 2012; Rosano et al., 2013; Hughes et al., 2018; Rensma et al., 2020). Aortic augmentation index, an indicator of arterial stiffness, is also related to white matter hyperintensities in post-menopausal females (Barnes et al., 2017). However, no other studies have examined sex differences in the relation between cerebral small vessel disease and arterial stiffness.

Large artery stiffness is also related to lower brain volumes abnormalities and amyloid- $\beta$ deposition (Mitchell et al., 2011; Hughes et al., 2018). The causative nature of increased large artery stiffness on neurodegeneration and neuroinflammation was demonstrated in rodents (Sadekova et al., 2018). There is a suggestion that these relations between peripheral pulse pressure and neuropathology may have sex differences, as it was found that females had a stronger correlation between brachial pulse pressure and white matter microstructure changes (Reas et al., 2021). Notably, this strong correlation in females is only true early post-menopause, corresponding to the period of more rapid stiffening of the large arteries, and is not found for the group over 75 years of age (Reas et al., 2021). Thus, studies indicate an association between large artery stiffness and neuropathology, but the knowledge of how sex and sex hormones effect these relations is very limited.

\section{COGNITIVE FUNCTION}

Large artery stiffness, and the resultant cerebrovascular dysfunction, will potentially impact the brain, leading to cognitive impairment. The literature regarding sex differences in cognitive function in older adults is inconsistent. This is partly due to sex differences in the specific types of cognitive function that change with age. Older females typically score better on verbal tasks than males, while older males score better on visuospatial and motor coordination than females (Weiss et al., 2003). An important sex difference is that older females experience a more rapid cognitive decline, with the transition from mild cognitive impairment to $\mathrm{AD}$ occurring faster compared with age-matched males (Lin et al., 2015). There are numerous studies demonstrating a correlation between greater large artery stiffness and cognitive impairment. While most of these studies controlled for sex in their analyses, none of them report analysis specifically for sex differences in these relations (Hanon et al., 2005; Mitchell et al., 2011; Tarumi et al., 2011; Pase et al., 2016; Meyer et al., 2017; Rouch et al., 2018) except the study by Singer et al. In that study of subjects 70-90 years of age, a relation between large artery stiffness and memory was found in males, but not females (Singer et al., 2013). However, as the rapid progression of arterial stiffness occurs from 55 to 75 years of age in females, this study may have missed the key time for relations 
in females. In rodents, induced carotid artery stiffening leads to cognitive impairment, but these studies are limited to male rodents to date (Muhire et al., 2019). The sex differences in the relation of arterial stiffness and cognitive decline are likely more complex than just differences in sex hormones. For example, history of pregnancy and childbirth may contribute as hemodynamic properties of the aorta are associated with cognitive function in post-menopausal females, but a history of preeclampsia influences this association for some cognitive abilities (Miller et al., 2020). Therefore, more research is needed to understand how sex may influence the effects of large artery stiffness on cognitive function.

\section{PERSPECTIVES: A TWO-HIT HYPOTHESIS FOR FEMALE BRAIN AGING AND REMAINING GAPS IN KNOWLEDGE}

The current hypothesis is that an age-related increase in large artery stiffness and pulse pressure leads to cerebrovascular and cognitive impairment. As the age-related stiffening of the large arteries is slower to progress in males, this may allow time for adaptation of the cerebral vasculature to elevated pulse pressure. In females, post-menopause, there is a more rapid increase in arterial stiffness, and this coincides with the loss of estrogen's protective effects on endothelial cells. Thus, early postmenopausal females are susceptible to two-hits simultaneously that can lead to cerebrovascular and cognitive impairment, and this may explain the increased $\mathrm{AD}$ risk in females.

A few factors have led to the paucity of data regarding sex differences in the effects of large artery stiffness on AD-related outcomes, such as the historical exclusion of females from studies and the treatment of sex as a confounding variable rather than an important contributor to physiology. In addition, ovariectomy is often used to induce a menopause-like state in young rodents matching human surgically induced menopause; however, this is distinctly different from natural human menopause as 1) the

\section{REFERENCES}

Aanerud, J., Borghammer, P., Rodell, A., Jónsdottir, K. Y., and Gjedde, A. (2017). Sex Differences of Human Cortical Blood Flow and Energy Metabolism. J. Cereb. Blood Flow Metab. 37 (7), 2433-2440. doi:10.1177/0271678X16668536

Alwatban, M. R., Aaron, S. E., Kaufman, C. S., Barnes, J. N., Brassard, P., Ward, J. L., et al. (2021). Effects of Age and Sex on Middle Cerebral Artery Blood Velocity and Flow Pulsatility index across the Adult Lifespan. J. Appl. Physiol. 130 (6), 1675-1683. doi:10.1152/japplphysiol.00926.2020

Alzheimer's Association (2013). Alzheimer's Disease Facts and Figures. Alzheimers Dement 9 (2), 208-245. doi:10.1016/j.jalz.2013.02.003

Barnes, J. N., and Charkoudian, N. (2021). Integrative Cardiovascular Control in Women: Regulation of Blood Pressure, Body Temperature, and Cerebrovascular Responsiveness. FASEB j. 35 (2), e21143. doi:10.1096/fj.202001387R

Barnes, J. N., Harvey, R. E., Zuk, S. M., Lundt, E. S., Lesnick, T. G., Gunter, J. L., et al. (2017). Aortic Hemodynamics and White Matter Hyperintensities in Normotensive Postmenopausal Women. J. Neurol. 264 (5), 938-945. doi:10.1007/s00415-017-8476-1

Berry, K. L., Cameron, J. D., Dart, A. M., Dewar, E. M., Gatzka, C. D., Jennings, G. L., et al. (2004). Large-Artery Stiffness Contributes to the Greater Prevalence of effects of estrogen deficiency may impact young and old females differently, and 2) human menopause typically does not have a sudden onset of estrogen loss (Diaz Brinton, 2012). Lastly, differences in the age of subjects may contribute to inconsistencies in the literature, as the rapid increase in arterial stiffness and cognitive decline are typically only found before the age of 75 years in females. Therefore, future studies need to include females in peri- and early post-menopause to understand these key physiological changes.

\section{CONCLUSION}

Age-related increases in large artery stiffness are associated with cerebral endothelial cell dysfunction, reduced cerebral blood flow, neuropathology, and cognitive impairment. As females experience a more rapid increase in large artery stiffness with aging, coinciding with menopause, they could be more susceptible to these damaging effects, and this may explain their increased risk for $\mathrm{AD}$ (Figure 1). These deleterious effects of increased large artery stiffness in older females likely contribute to other neurological diseases in addition to AD. Numerous efforts, in both human and animal studies, are needed to close the gaps in knowledge about the effects of vascular aging on the female brain.

\section{AUTHOR CONTRIBUTIONS}

MK and AW drafted, edited, and revised the manuscript, prepared the figure, and approve of the final version.

\section{FUNDING}

This work was supported by National Institutes of Health R01 AG064016 and the John L. Luvaas Family Fund.

Systolic Hypertension in Elderly Women. J. Am. Geriatr. Soc. 52 (3), 368-373. doi:10.1111/j.1532-5415.2004.52107.x

Coutinho, T. (2014). Arterial Stiffness and its Clinical Implications in Women. Can. J. Cardiol. 30 (7), 756-764. doi:10.1016/j.cjca.2014.03.020

Daneman, R., and Prat, A. (2015). The Blood-Brain Barrier. Cold Spring Harb Perspect. Biol. 7 (1), a020412. doi:10.1101/cshperspect.a020412

de Montgolfier, O., Pinçon, A., Pouliot, P., Gillis, M.-A., Bishop, J., Sled, J. G., et al. (2019). High Systolic Blood Pressure Induces Cerebral Microvascular Endothelial Dysfunction, Neurovascular Unit Damage, and Cognitive Decline in Mice. Hypertension 73 (1), 217-228. doi:10.1161/ HYPERTENSIONAHA.118.12048

Diaz Brinton, R. (2012). Minireview: Translational Animal Models of Human Menopause: Challenges and Emerging Opportunities. Endocrinology 153 (8), 3571-3578. doi:10.1210/en.2012-1340

Donato, A. J., Morgan, R. G., Walker, A. E., and Lesniewski, L. A. (2015). Cellular and Molecular Biology of Aging Endothelial Cells. J. Mol. Cell Cardiol. 89 (0 0), 122-135. doi:10.1016/j.yjmcc.2015.01.021

DuBose, L. E., Boles Ponto, L. L., Moser, D. J., Harlynn, E., Reierson, L., and Pierce, G. L. (2018). Higher Aortic Stiffness Is Associated with Lower Global Cerebrovascular Reserve Among Older Humans. Hypertension 72 (2), 476-482. doi:10.1161/HYPERTENSIONAHA.118.11143 
DuPont, J. J., Kenney, R. M., Patel, A. R., and Jaffe, I. Z. (2019). Sex Differences in Mechanisms of Arterial Stiffness. Br. J. Pharmacol. 176 (21), 4208-4225. doi:10.1111/bph.14624

DuPont, J. J., Kim, S. K., Kenney, R. M., and Jaffe, I. Z. (2021). Sex Differences in the Time Course and Mechanisms of Vascular and Cardiac Aging in Mice: Role of the Smooth Muscle Cell Mineralocorticoid Receptor. Am. J. Physiology-Heart Circulatory Physiol. 320 (1), H169-H180. doi:10.1152/ ajpheart.00262.2020

Fonck, E., Feigl, G. G., Fasel, J., Sage, D., Unser, M., Ruifenacht, D. A., et al. (2009). Effect of Aging on Elastin Functionality in Human Cerebral Arteries. Stroke 40 (7), 2552-2556. doi:10.1161/STROKEAHA.108.528091

Fuentes, N., and Silveyra, P. (2019). Estrogen Receptor Signaling Mechanisms. Adv. Protein Chem. Struct. Biol. 116, 135-170. doi:10.1016/bs.apcsb.2019.01.001

Gatti, C. D., Osto, E., Kouroedov, A., Eto, M., Shaw, S., Volpe, M., et al. (2008). Pulsatile Stretch Induces Release of Angiotensin II and Oxidative Stress in Human Endothelial Cells: Effects of ACE Inhibition and AT1 Receptor Antagonism. Clin. Exp. Hypertens. 30 (7), 616-627. doi:10.1080/ 10641960802443183

Gavin, K. M., Seals, D. R., Silver, A. E., and Moreau, K. L. (2009). Vascular Endothelial Estrogen Receptor a Is Modulated by Estrogen Status and Related to Endothelial Function and Endothelial Nitric Oxide Synthase in Healthy Women. J. Clin. Endocrinol. Metab. 94 (9), 3513-3520. doi:10.1210/jc.20090278

Girão-Silva, T., Fonseca-Alaniz, M. H., Ribeiro-Silva, J. C., Lee, J., Patil, N. P., Dallan, L. A., et al. (2021). High Stretch Induces Endothelial Dysfunction Accompanied by Oxidative Stress and Actin Remodeling in Human Saphenous Vein Endothelial Cells. Sci. Rep. 11, 13493. doi:10.1038/s41598-021-93081-3

Hanon, O., Haulon, S., Lenoir, H., Seux, M.-L., Rigaud, A.-S., Safar, M., et al. (2005). Relationship between Arterial Stiffness and Cognitive Function in Elderly Subjects with Complaints of Memory Loss. Stroke 36 (10), 2193-2197. doi:10.1161/01.STR.0000181771.82518.1c

Harvey, R. E., Barnes, J. N., Hart, E. C. J., Nicholson, W. T., Joyner, M. J., and Casey, D. P. (2017). Influence of Sympathetic Nerve Activity on Aortic Hemodynamics and Pulse Wave Velocity in Women. Am. J. Physiology-Heart Circulatory Physiol. 312 (2), H340-H346. doi:10.1152/ajpheart.00447.2016

Hayashi, K., and Hirayama, E. (2017). Age-Related Changes of Wall Composition and Collagen Cross-Linking in the Rat Carotid Artery - in Relation with Arterial Mechanics. J. Mech. Behav. Biomed. Mater. 65, 881-889. doi:10.1016/ j.jmbbm.2016.10.007

Haynes, M. P., Sinha, D., Russell, K. S., Collinge, M., Fulton, D., Morales-Ruiz, M., et al. (2000). Membrane Estrogen Receptor Engagement Activates Endothelial Nitric Oxide Synthase via the PI3-Kinase-Akt Pathway in Human Endothelial Cells. Circ. Res. 87 (8), 677-682. doi:10.1161/01.RES.87.8.677

Holwerda, S. W., Luehrs, R. E., DuBose, L., Collins, M. T., Wooldridge, N. A., Stroud, A. K., et al. (2019). Elevated Muscle Sympathetic Nerve Activity Contributes to Central Artery Stiffness in Young and Middle-Age/Older Adults. Hypertension 73 (5), 1025-1035. doi:10.1161/ HYPERTENSIONAHA.118.12462

Hughes, T. M., Wagenknecht, L. E., Craft, S., Mintz, A., Heiss, G., Palta, P., et al. (2018). Arterial Stiffness and Dementia Pathology. Neurology 90 (14), e1248-e1256. doi:10.1212/WNL.0000000000005259

Iulita, M. F., Noriega de la Colina, A., and Girouard, H. (2018). Arterial Stiffness, Cognitive Impairment and Dementia: Confounding Factor or Real Risk? J. Neurochem. 144 (5), 527-548. doi:10.1111/jnc.14235

Jefferson, A. L., Cambronero, F. E., Liu, D., Moore, E. E., Neal, J. E., Terry, J. G., et al. (2018). Higher Aortic Stiffness Is Related to Lower Cerebral Blood Flow and Preserved Cerebrovascular Reactivity in Older Adults. Circulation 138 (18), 1951-1962. doi:10.1161/CIRCULATIONAHA.118.032410

Kapasi, A., and Schneider, J. A. (2016). Vascular Contributions to Cognitive Impairment, Clinical Alzheimer's Disease, and Dementia in Older Persons. Biochim. Biophys. Acta (Bba) - Mol. Basis Dis. 1862 (5), 878-886. doi:10.1016/ j.bbadis.2015.12.023

Kastrup, A., Dichgans, J., Niemeier, M., and Schabet, M. (1998). Changes of Cerebrovascular CO 2 Reactivity During Normal Aging. Stroke 29 (7), 1311-1314. doi:10.1161/01.STR.29.7.1311

Knutsen, R. H., Beeman, S. C., Broekelmann, T. J., Liu, D., Tsang, K. M., Kovacs, A., et al. (2018). Minoxidil Improves Vascular Compliance, Restores Cerebral
Blood Flow, and Alters Extracellular Matrix Gene Expression in a Model of Chronic Vascular Stiffness. Am. J. Physiology-Heart Circulatory Physiol. 315 (1), H18-H32. doi:10.1152/ajpheart.00683.2017

Krause, D. N., Duckles, S. P., and Pelligrino, D. A. (2006). Influence of Sex Steroid Hormones on Cerebrovascular Function. J. Appl. Physiol. 101 (4), 1252-1261. doi:10.1152/japplphysiol.01095.2005

Lee, S. J., Lenton, E. A., Sexton, L., and Cooke, I. D. (1988). The Effect of Age on the Cyclical Patterns of Plasma LH, FSH, Oestradiol and Progesterone in Women with Regular Menstrual Cycles. Hum. Reprod. 3 (7), 851-855. doi:10.1093/ oxfordjournals.humrep.a136796

Lefferts, W. K., DeBlois, J. P., Augustine, J. A., Keller, A. P., and Heffernan, K. S. (2020). Age, Sex, and the Vascular Contributors to Cerebral Pulsatility and Pulsatile Damping. J. Appl. Physiol. 129 (5), 1092-1101. doi:10.1152/ japplphysiol.00500.2020

Lin, K. A., Choudhury, K. R., Rathakrishnan, B. G., Marks, D. M., Petrella, J. R., and Doraiswamy, P. M. (2015). Marked Gender Differences in Progression of Mild Cognitive Impairment over 8 Years. Alzheimer's Demen. Translational Res. Clin. Interventions 1 (2), 103-110. doi:10.1016/j.trci.2015.07.001

Liu, C. K., Lyass, A., Larson, M. G., Massaro, J. M., Wang, N., D’Agostino, R. B., et al. (2016). Biomarkers of Oxidative Stress Are Associated with Frailty: the Framingham Offspring Study. Age (Dordr) 38 (1), 1. doi:10.1007/s11357-0159864-Z

Lu, Y., Pechlaner, R., Cai, J., Yuan, H., Huang, Z., Yang, G., et al. (2020). Trajectories of Age-Related Arterial Stiffness in Chinese Men and Women. J. Am. Coll. Cardiol. 75 (8), 870-880. doi:10.1016/j.jacc.2019.12.039

Mawuenyega, K. G., Sigurdson, W., Ovod, V., Munsell, L., Kasten, T., Morris, J. C., et al. (2010). Decreased Clearance of CNS $\beta$-Amyloid in Alzheimer's Disease. Science 330 (6012), 1774. doi:10.1126/science.1197623

Meyer, M. L., Palta, P., Tanaka, H., Deal, J. A., Wright, J., Knopman, D. S., et al. (2017). Association of Central Arterial Stiffness and Pressure Pulsatility with Mild Cognitive Impairment and Dementia: The Atherosclerosis Risk in Communities Study-Neurocognitive Study (ARIC-NCS). J. Alzheimers Dis. 57 (1), 195-204. doi:10.3233/JAD-161041

Miller, V. M., Jayachandran, M., Barnes, J. N., Mielke, M. M., Kantarci, K., and Rocca, W. A. (2020). Risk Factors of Neurovascular Ageing in Women. J. Neuroendocrinol 32 (1), e12777. doi:10.1111/jne.12777

Mitchell, G. F. (2018). Aortic Stiffness, Pressure and Flow Pulsatility, and Target Organ Damage. J. Appl. Physiol. 125 (6), 1871-1880. doi:10.1152/ japplphysiol.00108.2018

Mitchell, G. F., van Buchem, M. A., Sigurdsson, S., Gotal, J. D., Jonsdottir, M. K., Kjartansson, Ó., et al. (2011). Arterial Stiffness, Pressure and Flow Pulsatility and Brain Structure and Function: The Age, Gene/Environment Susceptibility Reykjavik Study. Brain 134 (11), 3398-3407. doi:10.1093/brain/awr253

Moreau, K. L., Gavin, K. M., Plum, A. E., and Seals, D. R. (2005). Ascorbic Acid Selectively Improves Large Elastic Artery Compliance in Postmenopausal Women. Hypertension 45 (6), 1107-1112. doi:10.1161/ 01.HYP.0000165678.63373.8c

Moreau, K. L., and Hildreth, K. L. (2014). Vascular Aging Across the Menopause Transition in Healthy Women. Adv. Vasc. Med. 2014, 204390. doi:10.1155/ 2014/204390

Moreau, K. L., Meditz, A., Deane, K. D., and Kohrt, W. M. (2012). Tetrahydrobiopterin Improves Endothelial Function and Decreases Arterial Stiffness in EstrogenDeficient Postmenopausal Women. Am. J. Physiology-Heart Circulatory Physiol. 302 (5), H1211-H1218. doi:10.1152/ajpheart.01065.2011

Morissette, M., Le Saux, M., D’Astous, M., Jourdain, S., Al Sweidi, S., Morin, N., et al. (2008). Contribution of Estrogen Receptors Alpha and Beta to the Effects of Estradiol in the Brain. J. Steroid Biochem. Mol. Biol. 108 (3), 327-338. doi:10.1016/j.jsbmb.2007.09.011

Morley, J. E. (2001). Androgens and Aging. Maturitas 38 (1), 61-71. doi:10.1016/ S0378-5122(00)00192-4

Muhire, G., Iulita, M. F., Vallerand, D., Youwakim, J., Gratuze, M., Petry, F. R., et al. (2019). Arterial Stiffness Due to Carotid Calcification Disrupts Cerebral Blood Flow Regulation and Leads to Cognitive Deficits. J. Am. Heart Assoc. 8 (9), e011630. doi:10.1161/JAHA.118.011630

Natoli, A. K., Medley, T. L., Ahimastos, A. A., Drew, B. G., Thearle, D. J., Dilley, R. J., et al. (2005). Sex Steroids Modulate Human Aortic Smooth Muscle Cell Matrix Protein Deposition and Matrix Metalloproteinase Expression. Hypertension 46 (5), 1129-1134. doi:10.1161/01.HYP.0000187016.06549.96 
Pase, M. P., Beiser, A., Himali, J. J., Tsao, C., Satizabal, C. L., Vasan, R. S., et al. (2016). Aortic Stiffness and the Risk of Incident Mild Cognitive Impairment and Dementia. Stroke 47 (9), 2256-2261. doi:10.1161/ STROKEAHA.116.013508

Pau, C. Y., Pau, K-Y. F., and Spies, H. G. (1998). Putative Estrogen Receptor $\beta$ and $\alpha$ mRNA Expression in Male and Female Rhesus Macaques. Mol. Cell Endocrinol. 146 (1), 59-68. doi:10.1016/S0303-7207(98)00197-X

Poels, M. M. F., Ikram, M. A., van der Lugt, A., Hofman, A., Niessen, W. J., Krestin, G. P., et al. (2012). Cerebral Microbleeds are Associated with Worse Cognitive Function: The Rotterdam Scan Study. Neurology 78 (5), 326-333. doi:10.1212/ WNL.0b013e3182452928

Qiu, H., Depre, C., Ghosh, K., Resuello, R. G., Natividad, F. F., Rossi, F., et al. (2007). Mechanism of Gender-Specific Differences in Aortic Stiffness with Aging in Nonhuman Primates. Circulation 116 (6), 669-676. doi:10.1161/ CIRCULATIONAHA.107.689208

Raignault, A., Bolduc, V., Lesage, F., and Thorin, E. (2017). Pulse PressureDependent Cerebrovascular eNOS Regulation in Mice. J. Cereb. Blood Flow Metab. 37 (2), 413-424. doi:10.1177/0271678X16629155

Reas, E. T., Laughlin, G. A., Hagler, D. J., Lee, R. R., Dale, A. M., and McEvoy, L. K. (2021). Age and Sex Differences in the Associations of Pulse Pressure with White Matter and Subcortical Microstructure. Hypertension 77 (3), 938-947. doi:10.1161/HYPERTENSIONAHA.120.16446

Rensma, S. P., van Sloten, T. T., Houben, A. J. H. M., Köhler, S., van Boxtel, M. P. J., Berendschot, T. T. J. M., et al. (2020). Microvascular Dysfunction Is Associated with Worse Cognitive Performance. Hypertension 75 (1), 237-245. doi:10.1161/ HYPERTENSIONAHA.119.13023

Robison, L. S., Gannon, O. J., Salinero, A. E., and Zuloaga, K. L. (2019). Contributions of Sex to Cerebrovascular Function and Pathology. Brain Res. 1710, 43-60. doi:10.1016/j.brainres.2018.12.030

Rosano, C., Watson, N., Chang, Y., Newman, A. B., Aizenstein, H. J., Du, Y., et al. (2013). Aortic Pulse Wave Velocity Predicts Focal White Matter Hyperintensities in a Biracial Cohort of Older Adults. Hypertension 61 (1), 160-165. doi:10.1161/HYPERTENSIONAHA.112.198069

Rouch, L., Cestac, P., Sallerin, B., Andrieu, S., Bailly, H., Beunardeau, M., et al. (2018). Pulse Wave Velocity Is Associated with Greater Risk of Dementia in Mild Cognitive Impairment Patients. Hypertension 72 (5), 1109-1116. doi:10.1161/HYPERTENSIONAHA.118.11443

Sadekova, N., Iulita, M. F., Vallerand, D., Muhire, G., Bourmoum, M., Claing, A., et al. (2018). Arterial Stiffness Induced by Carotid Calcification Leads to Cerebral Gliosis Mediated by Oxidative Stress. J. Hypertens. 36 (2), 286-298. doi:10.1097/HJH.0000000000001557

Scuteri, A., Lakatta, E. G., Bos, A. J. G., and Fleg, J. L. (2001). Effect of Estrogen and Progestin Replacement on Arterial Stiffness Indices in Postmenopausal Women. Aging Clin. Exp. Res. 13 (2), 122-130. doi:10.1007/BF03351534

Singer, J., Trollor, J. N., Crawford, J., O’Rourke, M. F., Baune, B. T., Brodaty, H., et al. (2013). The Association between Pulse Wave Velocity and Cognitive Function: The Sydney Memory and Ageing Study. PLOS ONE 8 (4), e61855. doi:10.1371/journal.pone.0061855

Strehlow, K., Rotter, S., Wassmann, S., Adam, O., Grohe', C., Laufs, K., et al. (2003). Modulation of Antioxidant Enzyme Expression and Function by
Estrogen. Circ. Res. 93 (2), 170-177. doi:10.1161/ 01.RES.0000082334.17947.11

Sweeney, M. D., Kisler, K., Montagne, A., Toga, A. W., and Zlokovic, B. V. (2018). The Role of Brain Vasculature in Neurodegenerative Disorders. Nat. Neurosci. 21 (10), 1318-1331. doi:10.1038/s41593-018-0234-x

Taddei, S., Virdis, A., Ghiadoni, L., Mattei, P., Sudano, I., Bernini, G., et al. (1996). Menopause Is Associated with Endothelial Dysfunction in Women. Hypertension 28 (4), 576-582. doi:10.1161/01.HYP.28.4.576

Tarumi, T., Shah, F., Tanaka, H., and Haley, A. P. (2011). Association Between Central Elastic Artery Stiffness and Cerebral Perfusion in Deep Subcortical gray and White Matter. Am. J. Hypertens. 24 (10), 1108-1113. doi:10.1038/ ajh.2011.101

Torres, M. J., Kew, K. A., Ryan, T. E., Pennington, E. R., Lin, C.-T., Buddo, K. A., et al. (2018). 17 $\beta$-Estradiol Directly Lowers Mitochondrial Membrane Microviscosity and Improves Bioenergetic Function in Skeletal Muscle. Cel Metab. 27 (1), 167-179. e7. doi:10.1016/j.cmet.2017.10.003

Vanhoutte, P. M., Shimokawa, H., Feletou, M., and Tang, E. H. C. (2017) Endothelial Dysfunction and Vascular Disease - a 30th Anniversary Update. Acta Physiol. 219 (1), 22-96. doi:10.1111/apha.12646

Waddell, T. K., Dart, A. M., Gatzka, C. D., Cameron, J. D., and Kingwell, B. A. (2001). Women Exhibit a Greater Age-Related Increase in Proximal Aortic Stiffness Than Men. J. Hypertens. 19 (12), 2205-2212. doi:10.1097/00004872200112000-00014

Walker, A. E., Henson, G. D., Reihl, K. D., Morgan, R. G., Dobson, P. S., Nielson, E. I., et al. (2015). Greater Impairments in Cerebral Artery Compared with Skeletal Muscle Feed Artery Endothelial Function in a Mouse Model of Increased Large Artery Stiffness. J. Physiol. 593 (Pt 8), 1931-1943. doi:10.1113/ jphysiol.2014.285338

Weiss, E. M., Kemmler, G., Deisenhammer, E. A., Fleischhacker, W. W., and Delazer, M. (2003). Sex Differences in Cognitive Functions. Personal. Individual Differences 35 (4), 863-875. doi:10.1016/S0191-8869(02)00288-X

Zimmerman, M. A., Budish, R. A., Kashyap, S., and Lindsey, S. H. (2016). GPERNovel Membrane Oestrogen Receptor. Clin. Sci. (Lond). 130 (12), 1005-1016. doi:10.1042/CS20160114

Conflict of Interest: The authors declare that the research was conducted in the absence of any commercial or financial relationships that could be construed as a potential conflict of interest.

Publisher's Note: All claims expressed in this article are solely those of the authors and do not necessarily represent those of their affiliated organizations, or those of the publisher, the editors and the reviewers. Any product that may be evaluated in this article, or claim that may be made by its manufacturer, is not guaranteed or endorsed by the publisher.

Copyright (c) 2021 Kehmeier and Walker. This is an open-access article distributed under the terms of the Creative Commons Attribution License (CC BY). The use, distribution or reproduction in other forums is permitted, provided the original author(s) and the copyright owner(s) are credited and that the original publication in this journal is cited, in accordance with accepted academic practice. No use, distribution or reproduction is permitted which does not comply with these terms. 